\title{
Recent trends in the development of lifelong inclusive education of persons with disabilities in the Russian Federation
}

\author{
Oksana Prikhodko ${ }^{1 *}$, Victoria Manuylova ${ }^{1}$, Ascha Huseynova $^{1}$, and Olesya Yugova ${ }^{1}$ \\ ${ }^{1}$ GAOU VO MGPU, ISO \& KR, 119261, Moscow, Russia
}

\begin{abstract}
The article is devoted to the organization and implementation of lifelong inclusive education for children with special healthcare needs and disabilities at various age stages; reveals key aspects of the implementation of inclusive education in the early, preschool and adolescence stages, as well as at the stage of professional education. It describes the special conditions for access to a high-quality education of children with special educational and reveals some problems of inclusive education. Significant attention is given to the issues of tolerance within the context of inclusive education for persons with special healthcare needs and disabilities.
\end{abstract}

One of the major objectives of the national policy of Russian Federation is to create conditions for providing people with special healthcare needs (hereinafter referred to as PSHCN) with equal access to high-quality education in general educational and other educational organizations while taking into account the peculiarities of people's psychophysical development and the recommendations of Psychological, Medical and Pedagogical Commissions [1].

At the present stage of the education, the main goal is to ensure that children with special educational needs receive high-quality lifelong education from an early age until graduation from a vocational institution. The development of the principles of continuity, accessibility, and sustainability between all the levels and stages of education is prioritized. We consider lifelong inclusive education as a necessary condition for organizing lifelong learning, development, and upbringing of children with special educational needs, providing them with the social and psychological, pedagogical and rehabilitation assist at all levels of education, creating an adaptive environment for each child.

In terms of the optimum strategy for access to lifelong inclusive education, it is required to highlight the importance of including children with developmental disabilities in activities with peers as early as possible. Early systematic assist helps to achieve amazing results: it helps to correct developmental disorders and even overcome them. Early assist services and other forms of early development and rehabilitation of developmental disorders lay the basis for further inclusion to let people with disabilities be included in society [2].

The early Medical Psychological and Pedagogical assist children and family foster the productivity of their further inclusion in the society at all stages of education, and also

\footnotetext{
${ }^{*}$ Corresponding author: oksanadean@,mail.ru
} 
promotes the development of tolerance. This is due to the fact that the differences between normally developing children and persons with special healthcare needs are vaguely noticed, moreover, their perception is not yet influenced by other people's stereotypes and views, it is invaluable. They tolerate special features and differences much better than older children or adults, and it is easier for children with special healthcare needs to join the common activities with their peers. Creating optimal conditions for the joint education of children with normative development and children with various violations requires a fundamental restructuring of the education system. Restructuring measures and introducing new approaches can be carried out easier for all the participants in the educational process at the stage of preschool education.

An important role in the formation of an inclusive culture is given to the cooperation of the educational institutions and the family of children with developmental disabilities, as well as the interaction of parents of children with disabilities with parents of normally developing children. The early inclusion of children with special needs in the environment of healthy peers helps to reduce the psychological trauma of their parents, but isolation, especially prolonged one, and segregation, negatively affect both the psychological health of adults and the relationships in the family between a parent and a child [3].

Currently, all children with special healthcare needs are included in the learning environment. For this purpose, each educational organization should comply with the terms of recruitment of qualified personnel as well as meet the material, technical, financial, educational and methodological conditions to provide successful and productive learning.

Defining the specific conditions for access to quality education for children with special educational needs at various age stages is carried out by the Psychological, Medical and Pedagogical Commission (PMPC).

Creating an appropriate human resources environment is one of the core directions of the educational organization in training persons of different nosologies. The staff of the educational organization should include an interdisciplinary team of the assistance of welltrained specialists who know the peculiarities of the psychophysical development of children with special education and use all the range of teaching technologies and techniques. It is compulsory to include a speech therapist must in an interdisciplinary team in case of any speech disorders. A significant part of students with special educational needs has vision impairment. Thus, the vision impairment teacher must be also be included in the multidisciplinary team both for diagnostics and training. A teacher for deaf and dumb children should be involved in the training of persons with hearing impairment. The psychologist must also be an obligatory member of an interdisciplinary team of specialists supporting students with special healthcare needs. Teaching children with intellectual disabilities should be carried out by a special intellectual disability teacher who knows the features of the development of persons in this category. A tutor may be included, especially when recommended by PMPC for a particular student, and (or) an assistant may be recommended by the bureau of medical and social expertise

The material and technical terms of an educational organization for the inclusion of children in this category should meet both general requirements and special educational needs.

Carrying out a successful and productive learning process of children with special healthcare needs require special educational and methodological support. Owing to motor, speech, sensory, cognitive impairments, students in this category an individual differentiated approach to training and education is recommended.

Financial support of the state for students with special educational needs to access available and free education is based on the standards determined by state authorities of the constituent entities of the Russian Federation. 
In our country, there is a fairly extensive system of preschool and school rehabilitation education, and a whole network of special institutions corresponding to certain health disorders. Unfortunately, with the rapid implementation of inclusion ideas, the number of corrective educational organizations is decreasing.

In recent years, educational institutions have been moving from one form of education for children with disabilities - rehabilitation, to another - inclusive. Statistics of recent years prove the change of priorities. So, according to the Federal State Statistics Service, for 20102013 there was a sharp decrease in the number of kindergartens of a compensating type by $22 \%$. The number of kindergartens of supervision and rehabilitation type decreased by $17 \%$, and the primary schools of kindergartens of a compensating type decreased by $35 \%$. In contrast, there was a slight increase in the number of kindergartens of a combined type only by $3 \%$, and primary schools-kindergartens increased by $4 \%$. It is difficult to say how relevant the existing network of compensating kindergartens to the needs of children with disabilities and children with disabilities, since statistics do not give the number of children with special healthcare needs and disabilities visiting these institutions. Thus, the figures show that in general there is a decrease in forms of special education.

At present, it is necessary to mention the problems of inclusive education, many of which are successfully solved in the context of special (rehabilitation) education:

- The qualifications of the staff are insufficient to provide quality training for children with special educational needs. Primary school teachers, as well as subject teachers, are trained to conduct basic learning and are not able to deal with all the variants of deviant development and to meet their educational needs. Even regular professional training is incapable of providing the entire huge layer of knowledge in all forms of dysontogenesis and differentiated approaches in working with them.

- It is difficult to make material and technical equipment of educational institutions and universal for all categories of children with disabilities.

- A large number of children in classes/groups makes it does not allow enough attention to be given to each student. The same is applied to normally developing but it is especially vital for children with special healthcare needs. It can be solved with the help of tutors, but their actual number is much less than the number of children who need them. It is also quite problematic to combine general educational curricula with adapted ones.

- Implementation of fully inclusive education requires significant investments larger than for the implementation of special (rehabilitation) education.

Maintaining special education is necessary not as a manifestation of discrimination against children with disabilities, but in order to provide some of them (children with intellectual disabilities, severe motor impairments, and severe autism spectrum disorders) with optimal conditions for obtaining a quality education.

One of the trends of the national educational policy in the Russian Federation is the introduction and development of inclusive education and it faces many problems of a different spectrum. In addition to material and technical difficulties in organizing an accessible environment and the necessity for advanced staff, it is necessary to point out not but note the insufficient level of tolerance towards people with developmental problems in our country. Moreover, negative perception of children with disabilities and unwillingness of normally developing children to study with CSHCN comes initially from their parents and as a consequence, it is transmitted by their children.

Tolerance is an essential characteristic of a mature person who accepts and respects the characteristics of other people, allowing a difference in their worldview and values. The Declaration of the Principles of Tolerance, approved by the UNESCO General Conference on November 16, 1995, is based on the principle of unconditional respect for human rights, despite diversities, which should not be an obstacle to their recognition as equal members of the society with the right to preserve their individuality. In 2011-2016 the Ministry of 
Education and Science of the Russian Federation implemented the state program "Accessible Environment" program, one of the main tasks of which was to develop a tolerant attitude towards people with special healthcare needs and disabilities in the communication aspect. But there is still much to be done in that direction.

For the successful development of inclusive education of schoolchildren, teachers and psychologists of secondary schools need to solve the following problems:

- study the development of tolerance and communication skills of adolescent children with disabilities;

- to develop and test individual adolescence psychological and pedagogical curricula of assist aimed at developing self-awareness, the establishing of self-esteem, and the assimilation of educational curricula.

To solve these problems, along with the objectives of inclusive education mentioned above distance learning centers are created in most educational organizations. Education in distance learning centers is recommended for people with special health care needs as well as children with disabilities who do not have medical contraindications to use a personal computer. The main tasks of distance education centers are education of persons. Using distance education makes individual approach to each student with various developmental disabilities possible while regarding their needs. Distance learning allows teachers to work with children at a convenient time and make the process self-paced. Among other advantages of distance learning we can mention cost-saving due to unnecessary rental premises, and superfluous travel to the place of study for both students and teachers. It also provides the inclusion of a large number of students with developmental disabilities in the educational process, improving the quality of education through the use of innovative means.

The necessity of vocational self-determination is an important component of the social situation in the development of high school students, including those who have various disabilities. Visual, hearing, motor impairment, chronic somatic and mental illnesses lead to disabilities and limit the possibilities of social integration. It is required to assist students to realize their vocational self-determination while they still go to school, taking into account their inclinations and abilities on the one hand, and the existing limitations on the other.

Inclusive secondary vocational education is an integral part of continuing education. Professional self-actualization is of great importance for people with special healthcare needs and disabilities. The legislation of the Russian Federation (the state program "Accessible Environment", the state program "Education") guarantees persons with special healthcare needs the creation of special conditions for professional education.

In 2016, in the constituent entities of the Russian Federation, on the initiative of the Ministry of Education and Science basic vocational education and training organizations (hereinafter referred to as BVETOs) and resource teaching and methodological centers of secondary vocational education and training (hereinafter referred to as RMTC SVET) began to appear. At present 112 basic vocational education and training organizations have been created in 82 constituent entities of the Russian Federation to support regional systems of inclusive secondary vocational education. Basic vocational education and training organizations are created based on vocational education and training organizations, which play a leading role in the field of inclusive secondary vocational education in the subjects.

The main purpose of BVETOs is the development of an inclusive secondary vocational education and training system that provides organizational and methodological support for the vocational education of persons with special healthcare needs and disabilities. The main tasks of BVETOs are to provide an accessible architectural environment on the territory of the organization, to provide with special equipment, including the equipment of collective use, as well as modern technical means and software to meet the educational needs of students with special healthcare needs and disabilities [4]. 
The websites of basic vocational education and training organizations are adapted to the peculiarities and needs of potential applicants from among persons with special healthcare needs and disabilities, contain a section in which all the information about inclusive vocational education and training is.

Teachers and employees of basic vocational organizations have accomplished further training courses on inclusive education. For effective training of persons with special healthcare needs and disabilities, adapted professional programs and methodological support for them have been developed. Comprehensive assist to students with special healthcare needs and disabilities is carried out during the entire period of training in basic vocational education and training organizations.

An important component of BVETO activities is early career guidance and the promotion of the employment of graduates from among students with special healthcare needs and disabilities. During the period of the admission campaign, a helpline for the reception of persons with special healthcare needs and disabilities is created and operates in BVETO. The main function of the selection committee is to navigate applicants with special healthcare needs and disabilities, as well as their parents (legal representatives), to assist in vocational self-determination following the potential and needs.

Advisory and methodological support for the activities of BVETOs in the constituent entities of the Russian Federation is entrusted to the resource educational and methodological centers of secondary vocational education and training created in the federal districts.

Today, RMTC SVETs have been created in 31 constituent entities of the Russian Federation in 8 federal districts, in which resources of a methodological focus for training people with special healthcare needs and disabilities are concentrated in secondary vocational education and training and additional vocational education organizations. The collective use of these resources is carried out by educational organizations through networking with the RMTC.

There were created 13 RUMCs of additional vocational education were created in the Central Federal District, 8 RUMCs of additional vocational education, in the Volga Federal District, 4 RUMCs of additional vocational education, in the Northwestern Federal District, 2 RUMCs of additional vocational education in the Ural and North Caucasus Federal Districts respectively, 3 RMTC SVETs in the Siberian and Southern Federal Districts respectively, and 1 RMTC SVET in the Far Eastern Federal District.

The first RMTC SVETs were created in 2017 in 25 constituent entities of the Russian Federation and were divided by focus (competencies). The remaining six RMTC SVETs founded in 2018 became universal without a specific focus. The main functions of the RMTC SVET were expert and consulting support for the development of the main vocational educational curricula, adapted educational curricula, funds of assessment tools, and their review. Another important area of work of the RMTC is the methodological, information and analytical support of the activities of vocational education and training organizations in the field of inclusive secondary vocational education.

Thus, the implementation of the state policy in the field of training for skilled workers and employees, as well as mid-level specialists, is aimed at creating conditions in vocational education and training institutions for training people with special healthcare needs and disabilities in secondary vocational education and training curricula. This proves the development of all levels of lifelong inclusive education, which allows people with special healthcare needs and disabilities to carry out vocational self-determination and selfrealization.

\section{References}


1. I.Yu. Levchenko, O.G. Prikhodko, A.A. Huseynova, V.V. Manuylova, Inclusive education: Special Conditions for the Inclusion of Students with Disabilities in the Educational Environment (National Book Center, Moscow, 2018, Ser. Special psychology)

2. O.G. Prikhodko, The System of Early Comprehensive Differentiated Rehabilitation and Developmental assist for children with cerebral palsy (GBOU VPO MGPU, Moscow, 2009)

3. O.V. Yugova, Variable Strategies for Early Psychological and Pedagogical Assist for children with Developmental Disabilities and their family (GBOU VPO MGPU, Moscow, 2012)

4. V.V. Manuylova, Humanitarian sciences, 2 (38), 23-30 (2017) 